Portland State University

PDXScholar

$7-22-2021$

\title{
'There are No Bathrooms Available!': How Older Adults Experiencing Houselessness Manage their Daily Activities
}

Ellis Jourdan Hews

Portland State University

Follow this and additional works at: https://pdxscholar.library.pdx.edu/open_access_etds

Part of the Urban Studies Commons

Let us know how access to this document benefits you.

\section{Recommended Citation}

Hews, Ellis Jourdan, "'There are No Bathrooms Available!': How Older Adults Experiencing Houselessness Manage their Daily Activities" (2021). Dissertations and Theses. Paper 5742.

https://doi.org/10.15760/etd.7613

This Thesis is brought to you for free and open access. It has been accepted for inclusion in Dissertations and Theses by an authorized administrator of PDXScholar. Please contact us if we can make this document more accessible: pdxscholar@pdx.edu. 
'There are No Bathrooms Available!'

How Older Adults Experiencing Houselessness Manage their Daily Activities

by

\author{
Ellis Jourdan Hews
}

A thesis submitted in partial fulfillment of the requirements for the degree of

\author{
Master of Urban Studies \\ in \\ Urban Studies \\ Thesis Committee: \\ Paula Carder, Chair \\ Kacy McKinney \\ Andrée Tremoulet
}

Portland State University

2021 


\begin{abstract}
Older adults living unhoused encounter limitations and challenges that drastically decrease their wellbeing and quality of life. The purpose of my study was to understand how experiencing houselessness impacted older adults' ability to conduct their activities of daily living (ADLs) and instrumental activities of daily living (IADLs) within their communities. I conducted phone interviews with older adults aged 50 and older who experienced houselessness in the Portland metro area. The participants described the persons and places that shaped their community life when they were living unhoused, and they described how those entities intervened to alleviate barriers to daily activities. The data indicated that the community-level interventions notably improved older adults' ability to conduct their daily activities.
\end{abstract}




\section{Dedication}

This research is dedicated to my family. To my supportive and hilarious parents, Cora and Brian Hews, and to my sister, Jessica Hews, for inspiring me to pursue this journey, while offering her guidance along the way. A warm thank you to the special people who shared their lived experiences with me, and who made this research possible in the first place. 


\section{Table of Contents}

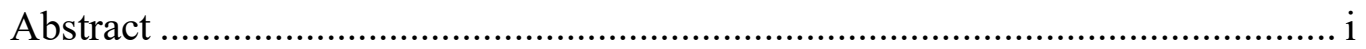

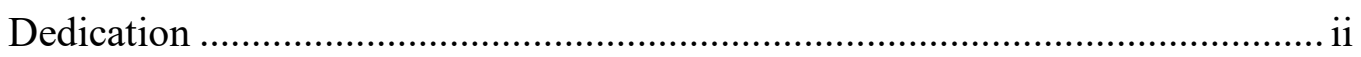

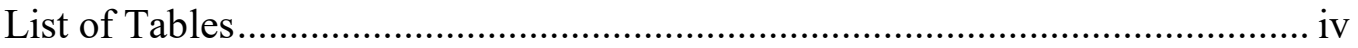

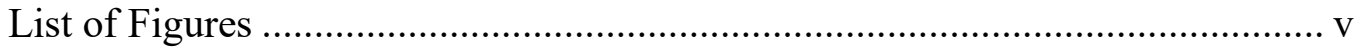

Chapter 1

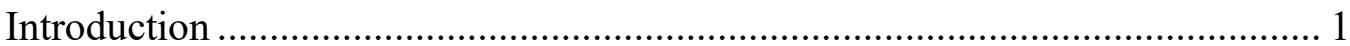

Chapter 2

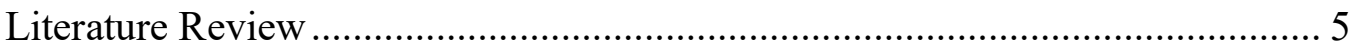

Chapter 3

Community Gerontology: A Framework for Analysis ................................... 22

Chapter 4

Research Design \& Methods.......................................................................... 24

Chapter 5

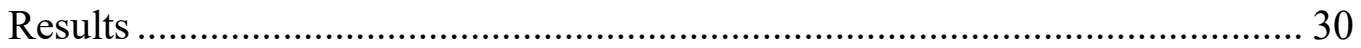

Chapter 6

Discussion, Policy Implications \& Future Research ...................................... 39

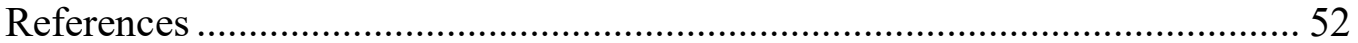


List of Tables

Table 1. Participant Characteristics............................................. 31 


\section{List of Figures}

Figure 1: Data Analysis, Qualitative Coding..................................... 33 


\section{CHAPTER 1: INTRODUCTION}

The purpose of this study was to understand how experiencing houselessness impacted older adults' ability to conduct their activities of daily living (ADLs) and instrumental activities of daily living (IADLs) within their communities. Through qualitative interviewing, I explored the daily experiences of older adults who experienced houselessness, as well as the challenges they encountered while living unhoused. The participants defined the term "community" from their own perspective, and then described how community-level entities impacted their ability to conduct their daily activities while they lived without housing. Activities of daily living (ADLs) include dressing, walking, transferring, bathing, and toileting; and instrumental activities of daily living (IADLs) include transportation, shopping, preparing meals, companionship, mental support, managing the household, medications, and finances, doing laundry, and communication with others (Edemekong et al., 2019; Kane \& Cutler, 2015). The ADL and IADL indices are traditionally used to understand whether an individual is able to perform these tasks independently (Katz et al., 1963; Graf, 2008). However, in this study I used the ADL and IADL indices to determine whether unhoused older adults were able to perform their daily activities without a consistent living environment.

In this study, I conducted nine semi-structured interviews and one go-along interview with formerly unhoused older adults who experienced houselessness in the Portland metro area when they were 50 years or older. The interview data indicated that the participants experienced a multitude of barriers that influenced the performance of their daily activities. Participants endured a loss of autonomy, which profoundly inhibited their quality of life. The participants described the persons and places that shaped their 
community life when they were living unhoused, and they described how those entities intervened to alleviate barriers to performing their daily activities. My data indicated that the community-level interventions notably improved older adults' ability to conduct their daily activities when they experienced houselessness.

\subsection{Background}

Houselessness in later life is a phenomenon that is rapidly increasing. Half of the adults experiencing houselessness in the US are 50 years or older, and the average age of this population is predicted to increase over time (Grenier et al., 2016; Kushel, 2019). According to the 2019 Point-In-Time Count of Homelessness in Portland, Gresham, and Multnomah County, Oregon, people experiencing unsheltered houselessness consisted of more aging individuals and persons with disabilities than what was reported in previous years (PIT Count of Homelessness in Portland/Gresham/Multnomah County, Oregon, 2019). In fact, $79 \%$ of individuals living unsheltered self-reported experiencing at least one disability, such as mental illness or a mobility limitation. The number of unhoused individuals 55 and older increased by $15 \%$ in two years (PIT Count of Homelessness in Portland/Gresham/Multnomah County, Oregon, 2019). The aging of the population of people experiencing houselessness is not unique to Multnomah County, or even the United States. Countries including Canada, Australia, and the United Kingdom are all experiencing a rapid growth in the number of people experiencing houselessness over the age of 50 (Grenier et al., 2016; Kushel, 2019).

Older adults living unhoused encounter limitations and challenges that drastically decrease quality of life and inhibit one's ability to conduct daily activities. The prevalence of multiple geriatric conditions (i.e. falls, cognitive impairment) and chronic 
diseases in this population is typical, and $30 \%$ of older adults experiencing houselessness report difficulties with performing their ADLs independently (Brown et al., 2015; Fried, 2012; Bazari et al., 2018; Cimino, 2015). The prevalence of ADL and IADL impairment in the population of older adults experiencing houselessness surpasses that of their housed counterparts aged 70 and older. A lack of housing greatly impacts the health and quality of life of older adults (Cimino, 2015; Brown et al., 2015).

\subsection{Problem statement and significance}

The population of older adults experiencing houselessness will not disappear any time soon. In fact, the quantity of older adults experiencing houselessness will grow over time because our world population is aging at a fast rate (Garibaldi, Conde-Martel, \& O'Toole, 2005). The Baby Boomer generation is growing older, and the number of older adults living unhoused will increase as a result (Hill, 2019; Gonyea et al., 2010). An estimated $44 \%$ of unhoused adults have their first experience with houselessness after the age of 50 (Kushel, 2019). This figure has immense implications for the older adult population because many older adults who become newly unhoused may experience difficulties modifying their new environment to suit their abilities (Kushel, 2011).

Houselessness profoundly impacts the health and wellbeing of older adults. Most (85\%) of unhoused adults 50 years and older report experiencing one or more chronic health conditions (Hahn et al., 2006). The population of older adults experiencing houselessness is enduring the same geriatric conditions that are typically associated with the aging experience (i.e. falls, cognitive decline), but this population is managing these conditions while living unhoused. And living unsheltered exacerbates health conditions that unhoused older adults manage on a daily basis (Hill, 2019; Ng et al., 2013). The 
mortality rates of this population are high, and the life expectancy is 64 years, which is significantly lower than the national life expectancy of 76 years (Metraux et al., 2011).

Many studies conclude that houselessness in later life is a dire issue that needs to be addressed. Researchers indicate that more qualitative data is needed to gain an indepth understanding about the houselessness experience (Petrusak, 2017; Cimino et al., 2015). More research about the unique experiences of older adults experiencing houselessness will help determine necessary solutions and services that will alleviate the aging houselessness crisis. My research contributes to the gap in this body of knowledge, by focusing on two key research questions: 1) How did the experience of houselessness impact older adults' ability to conduct their activities of daily living (ADLs) and instrumental activities of daily living (IADLs) within their communities? 2) What interventions occurred on the community level to improve the individual outcomes of older adults experiencing houselessness? 


\section{CHAPTER 2: LITERATURE REVIEW}

This research views houselessness in later life as a commonly under-explored facet in the urban studies and gerontology literature. Many studies conducted on houselessness focus on youth and family houselessness (Martijn \& Sharpe, 2006; Abramovich, 2012; Grant et al., 2013), while the majority of research explores the topic of houselessness more broadly, sans an aging lens (Hopper et al., 1997; BuschGeertseema, Culhane \& Fitzpatrick, 2016; Fransham \& Dorling, 2018). Research on the topic of houselessness in later life primarily comes from health-related disciplines, while older adults living unhoused are noticeably absent from the urban studies literature (Bazari et al., 2018; Brown et al., 2012). Urban studies research often omits the experiences of older adults experiencing houselessness from its sub-areas, such as urban livability, age-friendly research, and housing. These fields of research largely ignore the issue of houselessness and poverty among older adults (Liang et al., 2020; Noordzij et al., 2019; Smith et al., 2018).

The gerontology literature often excludes unhoused older adults from the ADLs and IADLs discourse entirely, since the activities of daily living (ADL) scale was created under the assumption that older adults are housed and capable of controlling their environment (Kim \& Kim, 2015; Mikkola et al., 2015; Mlinac \& Feng, 2016). The ADL scale is a central concept for gerontologists, dating back to the early 1960 s as a tool to understand level of acuity, chronic illness, and the services needed for an individual to live as independently as possible. Limitations to performing ADLs (bathing, dressing, toileting, transferring, continence, feedings), traditionally determines the individual's living environment (i.e. nursing home, home with caregiver) (Katz et al., 1963). The 
Lawton instrumental activities of daily living (IADL) scale is a tool gerontologists use to evaluate early functional deterioration in older adults. Chronic illnesses exacerbate one's ability to perform IADLs (i.e. managing finances, using the phone). Health professionals use this tool to determine services older adults may need if they experience difficulties in performing their IADLs (Graf, 2008). The ability to conduct ADLs and IADLs plays a significant role in the human experience, and individuals unable to perform these daily activities cannot live independently. Limitations to performing ADLs and IADLs impel individuals to modify their current environment, or transition into an environment that supports their abilities (Kane \& Cutler, 2015). Older adults experiencing houselessness do not have the capability to control their living environment to comply with their needs (Kushel, 2011).

Because houselessness among older adults is an underrepresented topic in the literature, there are only a few studies researching how living unhoused impacts older adults' ability to conduct their ADLs and IADLs in their community. My research is also concerned with understanding the interventions taking place on the community level to help older adults experiencing houselessness conduct their ADLs and IADLs. This literature review will examine studies related to this topic and its methodology, and evaluate the framework utilized to guide this research, community gerontology.

\subsection{The forms of houselessness}

The literature on houselessness typically uses the terms "homeless" and "homelessness" to describe individuals living without housing, but I chose to use the terms "houseless" and "houselessness" throughout my thesis. The logic behind this word choice was based on conversations with individuals who work with populations living 
unhoused; and derives from a recognition that one can have a place to call home without having a place to live.

The U.S. Department of Housing and Urban Development (HUD) defines "homeless" as an individual who "lacks a fixed, regular, and adequate nighttime residence" (HUD, 2018, p. 2). Individuals experiencing houselessness often depend on public space to sleep and perform their daily activities (Culhane et al., 2013). Living unsheltered can refer to sleeping or living in vehicles, outside, or in public places that are not intended for human occupancy (PIT Count of Homelessness in Portland/Gresham/Multnomah County, Oregon, 2019).

According to a 2018 report from the National Alliance to End Homelessness (NAEH), approximately 200,000 individuals sleep in unsheltered conditions on a typical night in the US (National Alliance to End Homelessness (NAEH), 2018). Over 50\% of American communities indicated a rise in the number of individuals experiencing unsheltered houselessness between the years 2015 and 2017. The spike in unsheltered houselessness was primarily aggregated in cities in the West, which was correlated with the western states' increase in housing costs (National Alliance to End Homelessness (NAEH), 2018; Khouri, 2018). In fact, the highest rates of unsheltered houselessness were clustered in Hawaii, California, Nevada, and Oregon (Khouri, 2018). The affordable housing crisis is reported to be one of the main causes of unsheltered houselessness (National Alliance to End Homelessness (NAEH), 2018).

The literature typically refers to four types of houselessness, which include: chronic, crisis, episodic, and transitional houselessness (Fazel et al., 2014; National Coalition for the Homeless, n.d.). Chronic houselessness is defined as "an individual with 
a disability who has been continuously homeless for one year or more or has experienced at least four episodes of homelessness in the last three years" (HUD, 2018, p. 2). The population of people experiencing chronic houselessness is disproportionately older (National Coalition for the Homeless, n.d.). The number of people experiencing chronic houselessness in Multnomah County, Oregon increased by 37\% since 2017 (PIT Count of Homelessness in Portland/Gresham/Multnomah County, Oregon, 2019). The nationwide PIT count indicated that almost 100,000 individuals were experiencing chronic houselessness in 2019 . That figure represents $24 \%$ of the whole population of people experiencing houselessness in the United States. Over $60 \%$ of those individuals experiencing chronic houselessness were sleeping unsheltered (National Alliance to End Homelessness (NAEH), 2020).

Crisis houselessness refers to a sudden event, such as eviction or death of a family member, that causes an individual to lose housing (Fazel et al., 2014; Kushel, 2019). Individuals who regularly experience brief or extended episodes of houselessness are considered to be episodically houseless. Individuals experiencing episodic houselessness are typically younger, often encountering a series of structural and personal barriers (National Coalition for the Homeless, n.d.; Institute of Medicine (US) Committee on Health Care for Homeless People, 1988; Canadian Observatory on Homelessness, n.d.). Individuals experiencing transitional houselessness live unhoused for a short period of time, typically 30 days or less. Similar to the characterization of episodic houselessness, individuals experiencing transitional houselessness are typically younger, living in unstable housing conditions prior to living unhoused (Canadian Observatory on Homelessness, n.d.; National Coalition for the Homeless, n.d.). 
It is immensely difficult to accumulate data on individuals who are not living unsheltered (Hoback \& Anderson, n.d.). The Canadian Observatory on Homelessness uses the term "hidden homelessness" to describe individuals who are coping with precarious living accommodations, often staying with relatives, friends or acquaintances (Canadian Observatory on Homelessness, n.d.). This housing situation is not a permanent solution. A common term to describe this phenomenon is "couch surfing." Individuals experiencing hidden homelessness are unable to pay for rent or other housing accommodations on their own income, and they must rely on the assistance from others within their networks (Canadian Observatory on Homelessness, n.d.). These individuals do not typically qualify for resources and services directed towards the population of people experiencing houselessness, even though their precarious living accommodations position them on a trajectory towards living without shelter (Canadian Observatory on Homelessness, n.d.; Pelley, 2017).

\subsection{Critical studies on older adults experiencing houselessness}

Because living unhoused exacerbates pre-existing health conditions and overall wellbeing, scholars argue that the US standard marker of older adulthood (65+) to describe older adults who are living unhoused should not be used (Gonyea et al., 2010; World Health Organization (WHO), n.d.). Scholars emphasize that individuals 50 years and older and experiencing houselessness must be categorized as older adults because this population is experiencing an unprecedented number of disabilities and geriatric conditions. These assertions informed my decision to include adults aged 50 years and older to take part in my study (Grenier et al., 2016; Kushel, 2011; Hill, 2019). 
The majority of scholars utilize quantitative research methods to explore various facets of houselessness in later life (Hahn et al., 2006; Cimino et al., 2015; Brown et al., 2015; Fazel et al., 2014). When conducting a 12-month study with a sample of older adults experiencing houselessness, Brown and colleagues (2015) discovered that acquiring housing significantly improved their quality of life (Brown et al., 2015). More specifically, the authors found that those who acquired housing decreased their use of health care services and improved their depressive symptoms. The researchers indicated that the most feasible solution for houselessness in later life is housing that supports the abilities of older adults with chronic conditions. A goal of this housing model is to enable older adults to live independently by providing them with the resources needed to modify their environment (Brown et al., 2015). Because researchers argue that a modifiable environment is vital for the wellbeing of unhoused older adults, we need more research on the unique challenges older adults encounter when conducting their ADLs and IADLs to acquire a broader understanding of their experiences (Brown et al., 2015).

A growing number of scholars identify a trend in houselessness research: the population of people experiencing houselessness is aging (PIT Count of Homelessness in Portland/Gresham/Multnomah County, Oregon, 2019; Hahn et al., 2006). This research highlights the importance of seeing this trend as an issue that needs scholarly and public attention. A significant share of the houselessness literature focuses on other groups experiencing houselessness (i.e. youth, families), but researchers are starting to recognize that these age groups are no longer the majority of the population of people experiencing houselessness (Martijn \& Sharpe, 2006; Hahn et al., 2006). According to the 2019 PointIn-Time Count of Homelessness in Portland, Gresham, and Multnomah County, Oregon, 
the number of individuals experiencing family and youth houselessness significantly decreased (PIT Count of Homelessness in Portland/Gresham/Multnomah County, Oregon, 2019). On the contrary, older houselessness in Multnomah County increased by $15 \%$ since 2017 , and the number of older adults living unhoused is expected to grow on a national level (PIT Count of Homelessness in Portland/Gresham/Multnomah County, Oregon, 2019).

The pattern of aging in Multnomah County's population of people experiencing houselessness is consistent with research conducted in other US cities. Hahn and colleagues (2006) argued that the average age of an unhoused individual increased from 37 to 46 years over a ten year period in San Francisco (Hahn et al., 2006). Chronic health conditions and hospital and emergency room usage proliferated over the same ten year period (Hahn et al., 2006). Fazel and colleagues (2014) would agree with the assertion that the population of people experiencing houselessness is growing older, arguing that people born between 1954 and 1965 are experiencing houselessness at an exponential rate when compared to other cohorts (Fazel et al., 2014). The findings in these studies indicate that the population of people experiencing houselessness is aging, and the studies allude to an urgent need for more research on this growing population (Fazel et al., 2014; Hahn et al., 2006). My study provides unique insight into the specific challenges this population encounters on a daily basis, while offering solutions that can optimize the quality of life of older adults experiencing houselessness.

Researchers argue there is a correlation between the presence of chronic health conditions and limitations in ADLs (Barile et al., 2012; Hwu, 1995). Varying health challenges can burden unhoused older adults (i.e. chronic illnesses, geriatric syndromes); 
therefore, we must focus our efforts on determining how these challenges influence their ability to perform their ADLs and IADLs (PIT Count of Homelessness in Portland/Gresham/Multnomah County, Oregon, 2019; Hahn et al., 2006). Cimino and colleagues (2015) discovered that $32 \%$ of unhoused older adults aged 50 and older reported difficulties performing one or more ADLs on a given day (Cimino et al., 2015). This finding is significant, and the researchers indicated that living unhoused exacerbated their ability to alleviate functional limitations (Cimino et al., 2015).

Other researchers discovered similar findings when researching ADL and IADL impairment and chronic illness among unhoused older adults. Brown and colleagues (2012) argued that unhoused older adults encounter difficulties with performing their ADLs and IADLs, and are more likely to experience an increase in geriatric conditions (i.e. frailty, vision impairment) and chronic health conditions (Brown et al., 2012). The high number of older adults experiencing houselessness is associated with increasing rates of chronic illness and geriatric conditions (Fazel et al., 2014). Older adults experiencing houselessness typically sustain geriatric conditions decades before their housed counterparts in the same age group (Fazel et al., 2014).

When conducting a community-based survey on unhoused adults residing in Philadelphia and Pittsburgh, PA, Garibaldi and colleagues (2005) discovered 85\% of unhoused older adults aged 50 and older reported experiencing a chronic health condition, and 74\% disclosed having a mental health disorder (Garibaldi et al., 2005). The researchers found that older adults experienced other challenges while living unhoused, such as locating community services and resources, physical \& sexual abuse, and dental health issues. Some of these challenges are unique to older adults, and the 
mortality rate for this population is significantly higher when compared to the younger, unhoused participants in the sample (Garibaldi et al., 2005). The researchers argued that housing, as well as access to health care services, are the primary needs of older adults experiencing houselessness (Garibaldi et al., 2005).

Researchers rely on other forms of qualitative methodologies to explore houselessness in later life. Tan (2018) conducted an ethnographic study with unhoused older adults residing in Singapore. The researcher indicated that unhoused older adults experienced a combination of structural and individual factors that heightened their risk for experiencing houselessness. In this study, structural factors can refer to the unavailability of government assistance, while individual factors can imply issues with familial or social support (Tan, 2018). The researcher emphasized the value of conducting an ethnographic study with this population, indicating that this methodology yielded dynamic observations and data that would be difficult to acquire in a quantitative study (Tan, 2018).

The topic of older adults who were formerly unhoused receives little attention in the literature, yet this population's experiences can provide invaluable insight for researchers studying houselessness in later life (WaldBrook, 2013; Souza et al., 2020). WaldBrook (2013) employed a mixed methods approach to understand how houselessness impacted the health and aging trajectories of women who were experiencing houselessness in Toronto, Canada (WaldBrook, 2013). All women secured housing, but the findings indicated that housing is not the sole remedy to alleviate the health and financial problems these participants encountered on a daily basis. The women discussed the importance of accessing free community resources that provided them with 
goods and services, such as food and healthcare. These community services were crucial, and an important staple in their daily life (WaldBrook, 2013). This study contributes to the literature on houselessness in later life, with findings suggesting that we must not disengage with older adults once they secure housing. Community support and resources are just as important for at risk individuals because it helps them maintain housing (WaldBrook, 2013).

There are fewer articles in the literature that indicate how the community (e.g. organizations, community service providers) responds to the growing number of older adults experiencing houselessness. Gonyea and colleagues (2010) argued that the majority of community-based aging services lack the capacity to accommodate the demands of unhoused older adults (Gonyea et al., 2010). These community-based organizations are unable to provide the proper resources to older adults suffering from chronic illnesses and mental health disorders, which are common among the older and unhoused communities (Gonyea et al., 2010). My research fills in this literature gap by evaluating community-interventions that optimize older adults' quality of life, while offering solutions as to how the community in Portland can better accommodate the needs of older adults experiencing houselessness.

2.3 Risk factors and causes of houselessness in later life

Researchers who study older adults experiencing houselessness discern a multitude of risk factors that are correlated with becoming unhoused in later life. Fazel and colleagues (2014) claimed that houselessness occurs when both individual (i.e. widowhood) and structural (i.e. lack of affordable housing) factors become intertwined in an individual's trajectory (Fazel et al., 2014). Prevalent factors that lead to houselessness 
include the dissolution of social support or relationships, loss of employment, or the occurrence of a life-altering event (Bazari et al., 2018; Ng et al., 2013).

$\mathrm{Ng}$ and colleagues (2013) determined various risk factors for houselessness in later life, (i.e. lack of housing, health issues), but they argued that the most typically experienced factors include unemployment, financial insecurity, and the absence of social support (Ng et al., 2013). Older adults may experience a life-altering event that causes them to lose housing, such as the death or loss of a caregiver, forced eviction, or a sudden decline in health (Gonyea et al., 2010; Bazari et al., 2018; Woolley, 2015). The results of Crane and colleagues' (2004) study revealed that $50 \%$ of older adults receiving Supplemental Security Income (SSI) reported that they were living alone in their household prior to losing housing (Crane et al., 2004). The results of this study indicate that declining social support and financial insecurity are risk factors for experiencing houselessness in later life (Crane et al., 2004; National Coalition for the Homeless, 2009).

Researchers argue that poverty and the inaccessibility of affordable housing are the primary causes of houselessness in later life (National Coalition for the Homeless, 2009; Kellogg \& Horn, 2013). Kushel (2019) would concur with this assertion, further arguing that $30 \%$ of adults 50 years and older spend more than $50 \%$ of their total income on rent (Kushel, 2019). The National Low Income Housing Coalition (2020) asserts that tenants should be paying $30 \%$ or less of their total income on rent (National Low Income Housing Coalition, 2020). But the high cost of rent is a factor that engenders low-income older adults to be at risk for houselessness, given the data that indicates a large percentage of older adults are expending the majority of their income on rent. The high cost of housing burdens older adults from spending money on other necessities, such as 
food \& nutrition, healthcare, and transportation (Kushel, 2019; National Low Income Housing Coalition, 2020; National Coalition for the Homeless, 2009; Goldberg et al., 2016).

Older adults relying on Social Security benefits alone can rarely afford to pay for housing without subsidies (National Coalition for the Homeless, 2009). A large number of low-income older adults depend on Social Security and SSI as their primary income, leaving a small percentage of their money for everyday necessities or financial emergencies (Goldberg et al., 2016). Entering or rejoining the workforce becomes a difficult option for older adults as they age, therefore making it challenging for them to rely on income generated from employment to pay for housing (National Coalition for the Homeless, 2009). Older women are especially vulnerable to houselessness. Women in older cohorts experienced a scarcity of full-time positions and high wage work, causing them to be most at risk for poverty and houselessness in later life (Woolley, 2015; Organisation for Economic Cooperation and Development (OECD), 2010).

Oregon, like many other states, is currently experiencing a scarcity of affordable housing units. As of 2019, there were only 28 affordable housing units accessible for every 100 low-income individuals or families living in Oregon (Kushel, 2019). On the national scale, there are only 37 affordable housing units accessible for every 100 lowincome individuals (National Low Income Housing Coalition, 2020). The demand for affordable housing is high, yet the supply for this type of housing is low (Kushel, 2019; Carter, 2011). This shortage directly impacts people living below the poverty line who are in need of stable housing, particularly low-income older adults (Kushel, 2019). Multiple factors have to occur in conjunction with one another in order for houselessness 
to transpire (Cohen, 1999). For example, a low supply of affordable housing and insufficient funds to pay rent are two factors that push individuals into houselessness if they occur concurrently (Carter, 2011; Cohen, 1999).

There are noteworthy patterns in this research on the causes and factors that force older adults into houselessness. The absence of fundamental necessities that help older adults maintain their independence (e.g. social support, financial stability) puts them at high risk for losing housing (Ng et al., 2013; Kushel, 2019; National Coalition for the Homeless, 2009).

2.4 ADLs and IADLs in the gerontology literature

Activities of daily living (ADLs) and instrumental activities of daily living (IADLs) are central concepts in the gerontology literature, and within the aging discourse more broadly (Wallace \& Shelkey, 2007; Carrière \& Légaré, 2000; Levine et al., 2003). Sidney Katz, the aforementioned pioneering scholar whose name is synonymous with ADLs research and application, determined the core activities of daily living, which include bathing, dressing, toileting, transferring, continence, and feeding (Katz et al., 1963). Personal hygiene is a primary component of the ADLs group, which include grooming, dental, and cuticle and hair maintenance (Edemekong et al., 2019). The Lawton instrumental activities of daily living (IADL) scale, created a few years after the ADL scale in 1969, was designed as a tool to evaluate an individual's ability to conduct more complicated daily activities independently (Graf, 2008). These activities include shopping, using the telephone, communication, transportation, medication management, housekeeping, food preparation, and managing finances (Szanton et al., 2011; 
Edemekong et al., 2019). Deterioration of ability to perform IADLs can be an early indicator of functional or cognitive decline (Graf, 2008).

Performing ADLs is essential for maintaining independence. The inability to conduct these activities negatively impacts quality of life (Edemekong et al., 2019). Chronic diseases and geriatric conditions can become more prevalent in later life, often impeding older adults' physical capacity to perform their ADLs (Edemekong et al., 2019). Szanton and colleagues (2011) argued that experiencing difficulties with one or more ADLs, or two or more IADLs, is a measure for indicating if an older adult is living with a disability (Szanton et al., 2011). Edemekong and colleagues (2019) indicated that transitioning into an institutional facility is often dependent upon one's capacity to perform their ADLs independently (Edemekong et al., 2019). The physical environment that one resides in influences their ability to conduct their ADLs and IADLs (Edemekong et al., 2019).

The ADL and IADL indices are perceived differently in other geographic locations and cultures. Jitapunkul and colleagues (1994) argued that the standard ADL index is not applicable to older adults living in Asia (Jitapunkul et al., 1994). There are fundamental differences in how these activities are performed in Asia, which bear minimal similarities to the index utilized in Western nations. The purpose of their study was to produce a culturally specific ADL index to assess the independence of older adults living in Asia (Jitapunkul et al., 1994). Jitapunkul and colleagues (1994) highlighted an important limitation of the ADL and IADL indices, which was the lack of usability across different cultures. The argument that Jitapunkl and colleagues (1994) constructed can be applicable to older adults living unhoused. Older adults experiencing houselessness do 
not have the capability to control their living environment, and they are not able to easily perform some of the standard ADLs and IADLs without housing (e.g., housekeeping, personal hygiene) (Kushel, 2011; Brown et al., 2015). My research explored how houselessness impacted older adults' ability to conduct their ADLs and IADLs while living unhoused, while simultaneously making the case for why the standard ADL and IADL indices should be modified when using them to evaluate older adults experiencing houselessness.

2.5 Qualitative interviewing \& the go-along method

Qualitative interviewing, the primary methodology utilized in this research study, helped me acquire in-depth data on the impact of houselessness on older adults' ability to conduct their ADLs and IADLs. Researchers often note the therapeutic quality that can be present in qualitative interviewing because it provides participants with the opportunity to share their experiences within a neutral space (Rossetto, 2014; Nelson et al., 2013). It is characteristic of qualitative research to have a small sample size with the purpose of focusing on the experiences of a few individuals. Qualitative research is not intended to be representative of the entire population, but it is vital to have adequate data to account for varying perspectives (Rossetto, 2014; Hallberg, 2008). Qualitative interviews are conducted with the purpose of acquiring stories and experiences, and to understand the sentiments the participants associate with their vocalized stories (Rossetto, 2014; Weiss, 1994). The primary expectation of a qualitative researcher is to hear the participants' experiences and learn from them (Rossetto, 2014).

A few scholars have examined the importance of listening to the stories of unhoused older adults through qualitative interviewing (Grenier et al., 2016; Bazari et al., 
2018; Kushel, 2019). When analyzing interviews conducted with unhoused older adults, researchers determined there are commonalities regarding their experiences with houselessness. Older adults indicated that houselessness created feelings of isolation and exclusion, and social relationships were arduous to maintain while living unhoused. Researchers indicated that the lack of social relationships exacerbated feelings of exclusion and isolation (Grenier et al., 2016; Bazari et al., 2018).

Bazari and colleagues (2018) conducted semi-structured interviews with older adults to gain perspective on the social, physical, and psychological feelings they encountered when experiencing houselessness (Bazari et al., 2018). The study discovered that living unhoused worsened psychological and physical symptoms for older adults, but the participants relied on various mechanisms (i.e. substance use, social relationships) to manage distress. The researchers determined that a solution to alleviate this distress is to provide older adults with housing that supports the cultivation of relationships within their community (Bazari et al., 2018). Qualitative interviewing helped the researchers acquire perspective on the older adults' sentiments, and it created a space for the participants to be introspective about their own experiences. This methodology proved to be ideal for understanding the feelings and concrete experiences of older adults living unhoused; the intimate details expressed by the participants may not have emerged using a different methodology. Qualitative interviewing helped the researchers determine meaningful solutions to the mental and physical challenges the participants experienced on a daily basis (Bazari et al., 2018).

The go-along method, the secondary method used in this study, is an underexplored method in social science research, especially in the gerontology field. Scholars 
across the social sciences utilize this method to explore how people interact with spaces and places that are a part of their daily routine (Groot \& Hodgetts, 2015; Garcia et al., 2012; Cameron et al., 2013). Researchers who used this method often comment on the value of incorporating mobility in research with human subjects. Mobile methodologies have a unique propensity to produce dynamic data and observations, all acquired through the mutual exploration of the participants' environment (Sheller \& Urry, 2006; Law \& Urry, 2004). Elwood and Martin (2000) argue that the location of the go-along interview alleviates the power dynamic that is present between the researcher and the participant (Elwood \& Martin, 2000). The go-along method facilitates the opportunity for the participant to shape the trajectory of the interview, which in turn creates an organic interview process (Garcia et al., 2012).

My research examined how experiencing houselessness impacted older adults' ability to conduct their ADLs and IADLs, and explored the community level interventions that helped to alleviate such challenges. Qualitative interviewing and the go-along interview provided context to the barriers older adults encountered in their daily environment. In my study, participants were able to share their perspectives and elaborate on pertinent details. Many participants commented on the therapeutic nature of personal reflection, as mentioned in the qualitative interviewing literature (Rossetto, 2014). With this method I was able to listen to the emotion in their voice when telling their stories. I became acquainted with the barriers they faced in their daily life, in addition to the interventions that were most beneficial to them during the period they were living unhoused. 


\section{CHAPTER 3: COMMUNITY GERONTOLOGY: A FRAMEWORK FOR ANALYSIS}

The framework of community gerontology guided the research and analysis of this study. This framework was introduced by Greenfield and colleagues (2018) in the gerontology literature. The authors define community gerontology as a practice that seeks to "...advance understanding of communities as fundamental contexts for aging and its diversity, and to leverage this understanding for change" (Greenfield et al., 2018, p. 803). The meso-level is the primary component of the community gerontology framework. It provides a foundation for understanding how the community, the individual, and the macro-level are interconnected. In this approach, the meso-level impacts an aging individual's wellbeing and quality of life (Greenfield et al., 2018). In the urban studies literature, researchers frequently evaluate how the meso-level impacts the micro-level experience in neighborhood revitalization and neighborhood effects research, often noting how an individual's quality of life can be negatively affected by their direct environment (Greenfield et al., 2018; Shelby, 2016; Fraser \& Kick, 2014). In my study, I explored the interventions on the community level that influenced older adults' ability to conduct their daily activities within their everyday environment.

The term "community" has multiple definitions in the literature. García, Giuliani \& Wiesenfeld (1999) argue that community is a term utilized to describe religious affiliations, business organizations and members that make up a neighborhood (García et al., 1999). Greenfield and colleagues (2018) do not define "community" within the context of community gerontology, but the researchers view the term more broadly, arguing that it must be composed of various definitions rooted in the viewpoints of different disciplines (Greenfield et al., 2018). When conducting the interviews, I did not 
provide the participants with definitions of "community," but I encouraged them to describe what their community life was like when they were living unhoused. The purpose of this exercise was to understand how entities at the community level intervened to alleviate barriers to performing daily activities, from the participants' perspective. After the interviews, I curated a series of definitions inspired by the participants' stories and understandings of their own community life. Based on the conversations with participants, "community" is composed of:

(a.) Organizations embedded in the fabric of the neighborhoods that serve people experiencing houselessness

(b.) Neighborhood places that are free and accessible to the general public

(c.) Community members stitched into the social fabric of neighborhoods

(d.) Peers within their social network bonded by the experience of houselessness

Greenfield and colleagues (2018) indicate that a vital pillar of community gerontology is gerontologists' ability to partake in "community-level change" with the purpose of increasing the wellbeing of aging groups (Greenfield et al., 2018). My study highlighted the importance of viewing interventions on the meso-level as vital for optimizing the quality of life of older adults living unhoused. The data helped me evaluate the interconnection of older individuals' perceived community and their daily activities. 


\section{CHAPTER 4: RESEARCH DESIGN \& METHODS}

\subsection{Study design}

I conducted nine semi-structured interviews and one go-along interview with formerly unhoused older adults aged 50 and older. Ten interviews were conducted in total. Interview data was collected by phone, with the exception of one go-along interview and one qualitative interview that took place in person, before the Covid-19 pandemic. Participants were recruited through community organizations in the Portland metro area who serve older adults, people experiencing houselessness, and low-income housing communities for older adults. I obtained verbal consent from each participant to partake in the research study. Participants received $\$ 10$ for their participation in the study. The institutional review board of Portland State University approved all activities related to this study.

\subsection{Setting and participants}

Participants were recruited during January 2020-June 2020. Participants were included in this study if they were English speaking, able to provide ongoing consent, and experienced houselessness when they were 50 years or older. See Table 1 below for participant characteristics. This study used the U.S. Department of Housing and Urban Development (HUD) definition of homeless to inform the latter criterion (HUD, 2018). I contacted representatives of the aforementioned community organizations and housing communities by email to recruit participants for this study. I provided these organizations with pertinent project details and a copy of my research study flier to pass along to individuals within their networks. Interested participants contacted me by phone or email. 
Table 1. Participant Characteristics

$(\mathbf{n}=9)$

\begin{tabular}{|c|c|}
\hline \multicolumn{2}{|l|}{ Gender Identity } \\
\hline Female & 5 \\
\hline Male & 3 \\
\hline Undisclosed & 1 \\
\hline \multicolumn{2}{|l|}{ Ethnicity } \\
\hline Hispanic/Latino/a & 1 \\
\hline Not Hispanic/ Latino/a & 1 \\
\hline \multicolumn{2}{|l|}{ Race } \\
\hline Black/African American & 1 \\
\hline Undisclosed & 7 \\
\hline \multicolumn{2}{|l|}{ Age (years) } \\
\hline Mean & 64 \\
\hline Range & $57-71$ \\
\hline
\end{tabular}

\subsection{Data collection}

Data was collected between February 2020- September 2020. Participants were interviewed one time during the study, with the exception of one participant who partook in one qualitative interview and one go-along interview. Each interview was approximately one hour. Interviews were recorded and uploaded on a secure computer. The recordings were transcribed using the transcription software Otter.ai. Identifying information in the transcripts were changed to pseudonyms. Memos were composed after each interview was completed.

\subsection{Data analysis}

I conducted thematic analysis by coding interview transcripts, utilizing applicable codes (e.g. places that help, privacy issues, transportation) to label the data (Fereday \& Muir-Cochrane, 2006). Transcripts were printed out and coded by hand using highlighters and post-it notes. Memos were composed during the preliminary round of coding to depict their value to the study, and refined following the second round of 
coding. I emulated Guest and colleagues' (2012) format for constructing a codebook, composing a brief and full definition for each code, along with an explanation of appropriate application per code (Guest et al., 2012). I enlisted the assistance of a second coder to increase the reliability of my analysis (Leung, 2015). The de-identified excerpts were cut and pasted on a wall, grouped together by content and code (see Figure 1 below). Themes emerged from the groupings, were assigned definitions, and supplemented with examples from the data. Themes were re-examined to ensure they were consonant with the data.

Figure 1: Data Analysis, Qualitative Coding

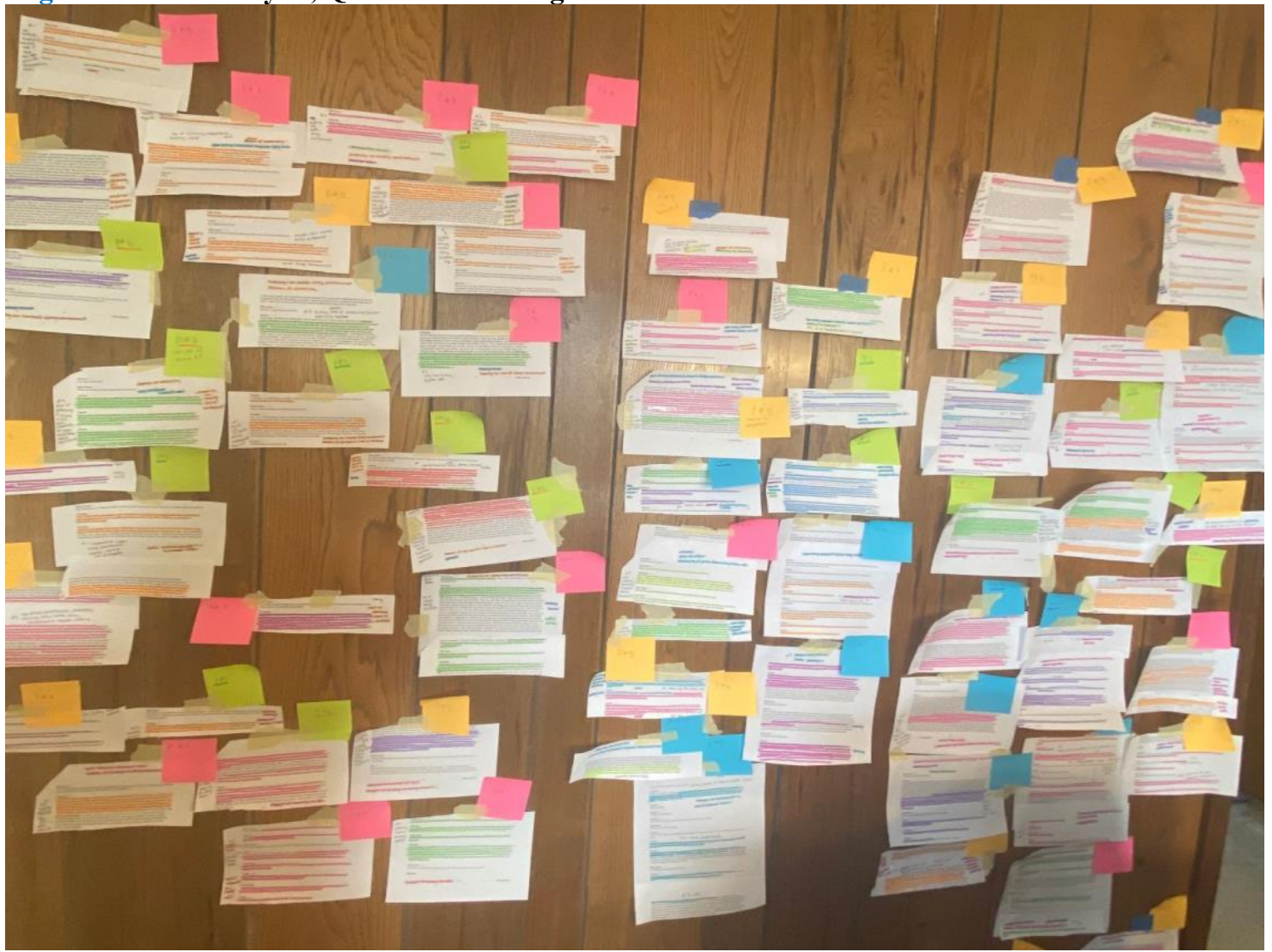




\subsection{Positionality}

My previous experiences working with older adults led to my interest in using qualitative research to acquire insight about older adults experiencing houselessness. I understand that I do not have the same lived experience as the participants; I am a young person with access to housing. I am also an outsider who is unfamiliar with the culture and relationships formed within this community. I recognize that my positionality influenced the codes I chose and my interpretation of the data, and I strived to maintain a balanced view that was informed by the literature and the voices that participated in this project.

\subsection{Limitations of research design \& methodology}

There are a few noteworthy limitations of this research design and methodology. The primary limitation was the small sample size that was assembled in this study. A small sample size inhibited the findings from achieving generalizability, but it is common to recruit a small sample in qualitative research because it enables researchers to acquire an in-depth perspective of participants' experiences (Crouch \& McKenzie, 2006). Qualitative studies in the literature that featured interviews with adults experiencing houselessness informed my decision to recruit nine participants for this study.

Second, the COVID-19 pandemic forced me to adjust my recruitment strategy and methodology. My transition from the go-along method to telephone interviews potentially excluded older adults who lack access to a phone from participating in this research study, and prevented the collection of context-specific data about the places where older adults experiencing houselessness managed their daily activities. Field research was suspended during the initial period of data collection, and the study's initial 
methodology, the go-along method, was deployed with only one participant. Because this study needed to be completed within a short time frame, the methodology was changed to phone interviews. The phone interviews permitted me to safely collect data during pandemic without putting the subject population at risk. But there were some notable barriers to phone interviewing. First, I was unable to establish face to face rapport with the participants, which is a vital component of qualitative interviewing. And the use of phone interviews most likely prevented individuals who do not have access to a phone or a private space from participating in this study. Phone interviews additionally prevented me from acquiring a dynamic understanding of the participants' neighborhoods. With the go-along method, the participants' neighborhoods provide context to their individual experiences (Sheller \& Urry, 2006; Law \& Urry, 2004). I was unable to visualize the participants' neighborhoods with phone interviews, so they were asked to describe their neighborhoods using their own stories and experiences. Because of these limitations, the subject population of this study only included formerly unhoused older adults, and no older adults currently experiencing houselessness participated in this study. The circumstances surrounding the pandemic prevented me from acquiring nuanced perspective from older adults currently living unhoused.

The Covid-19 pandemic also impacted my ability to recruit participants for this study. I was unable to continue to partake in an in-person recruitment strategy within Portland's neighborhoods. Before the pandemic, I was volunteering at a community organization who serves the unhoused community in an attempt to get to know older adults experiencing houselessness within a meaningful community setting. Volunteering at organizations within the Portland Metro area was a crucial component of my 
recruitment plan to be better acquainted with the population I intended to learn more about. As a recruitment strategy alternative, I recruited participants remotely, absent of face to face communication. The nature of accomplishing this task remotely stripped the study of the opportunity to recruit older adults currently experiencing houselessness. I suspected that it would be a challenge to recruit older adults living unhoused remotely, so I expanded my subject population to include formerly unhoused older adults. The limited time frame I was working with to complete this project prevented me from waiting for the opportunity to safely recruit the original subject population. 


\section{CHAPTER 5: RESULTS}

Four primary themes were discovered in relation to daily activities, community, and houselessness in later life. The themes include: ADLs and IADLs were challenging to perform, community life intervened to improve individual outcomes, loss of autonomy, and housing optimized quality of life.

5.1 ADLs and IADLs were challenging to perform

Bathroom facilities were inaccessible

Participants discussed the barriers they encountered when accessing bathrooms within their immediate environment. Many participants expressed that there was a shortage of accessible public bathrooms; restroom facilities were often closed off to people experiencing houselessness. One participant described their experience with trying to finding a bathroom around Downtown Portland:

When you're out and about doing business, you have to find someplace. But when you begin to look homeless, then people do not want to let you in the bathrooms. They just don't...I went into the train station to see if I can use the bathroom and they were like, well, are you here to get on a train or pick somebody up here? So I couldn't go in there. (Participant \#4)

Others alluded to the challenges of accessing bathroom facilities on a day-to-day

basis. One participant expressed:

...the city has closed all means and ways of privacy. That is for punishment...Because now we're forced to pee on the street...And I have no qualms or quarrels about spreading my fly with no dick to piss on the street because I can't get to a bathroom... When those bathrooms are closed, I have no choice. (Participant \#3)

Living unhoused impacted participants' ability to use the bathroom. They described the difficulties of locating bathroom facilities within their neighborhoods. The 
experience of houselessness made the act of using the bathroom a challenge to accomplish privately. Participants unable to use public bathroom facilities were subject to pursue other means of relieving themselves within public space.

\section{$\underline{\text { Keeping up with bathing and grooming was difficult }}$}

Participants discussed the challenges of keeping up with bathing and grooming while living unhoused. One participant elaborated on why they did not prioritize grooming when they were experiencing houselessness: "You're not thinking about getting a haircut. You are thinking about surviving. Everything has to be saved for transportation, food, and shelter." (Participant \#1)

Other participants noted the challenges of maintaining personal and dental hygiene, such as showering, keeping clothes clean, and flossing. Participants discussed the challenges of finding showers, getting to showers on time, and locating hygiene products. They also experienced financial barriers to accessing some hygienic necessities, such as toothpaste and laundry facilities.

\section{$\underline{\text { Deterioration of a sense of self }}$}

Participants discussed how living unhoused impacted their sense of self in relation to performing daily activities. One participant discussed how inaccessible bathroom facilities engendered their loss of dignity:

Let me tell you when you got a big yellow urine stain as wide as your hips, wearing a pair of blue jeans with a stench, well you fit in with your peers because they're doing the same thing. But you go into a bank or a coffee shop...you're embarrassed, you're degraded, you have no dignity, there's no respect. I didn't cause it. There's no bathrooms available! (Participant \#3)

Another participant discussed how living unhoused prevented them from 
frequently maintaining personal hygiene. This participant described how bathing and grooming were important for their identity:

...I would try to do everything I could every day to look like my old self and try to be like my old self as possible...and if I had money, we'd go to the community center and shower...Like these things, and I always felt like oh god, this [bathing] is helping me find a piece of myself again. (Participant \#9)

Participants discussed how living unhoused prevented them from performing some of their activities of daily living. This obstruction of daily activities impacted their sense of self, which engendered a loss of dignity and identity.

5.2 Community life intervened to improve individual outcomes Community organizations facilitated with ADLs and IADLs

Participants discussed how organizations in their community helped to make the performance of their ADLs and IADLs easier when living unhoused. One participant discussed how a community organization in Downtown Portland helped them get to their housing appointments by providing free public transit tickets:

And I used those tickets when I needed to go to subsidized buildings...I was able to get around in buildings that were out of the downtown area....and there's no way to get there until, you know, unless you have the little tickets to get around...if you don't have that ticket, you can't go anywhere. (Participant \#1)

Participants additionally discussed how these organizations became an important source of social support and companionship. One participant reflected on the support provided by a non-profit organization in Downtown Portland:

...I wouldn't have made it without the people that worked in those places. I mean, they would check in on you and make sure that you're doing ok, psychologically and emotionally and physically and everything else. (Participant \#8) 
Other participants discussed how some community organizations provided them with a safe and welcoming space to perform their ADLs (i.e., bathing, using the bathroom). Participants indicated that these organizations provided them with essential resources (e.g., weather appropriate clothing, hygiene products, telephone) that they otherwise did not have access to.

\section{Places that helped}

Participants discussed places they spent a lot of their free time on a day-to-day basis. These places helped fulfill a particular need in their quest to perform their daily activities. One participant discussed why they spent a lot of time at the public library:

Well, no matter what city you in, nobody can pick a better place than the library. In fact, I would have to say the library is a form of a day shelter...I would go to the library because I had my own private room...And you can always check your email online and get out of the cold. (Participant \#5)

Other participants indicated that the library provided them with free access to a computer, which was a helpful tool they used when searching for housing and employment opportunities. Another participant who lived outside indicated that they would walk around familiar public places when they encountered safety concerns in their own living environment.

\section{Community gatekeepers offered social support}

Participants discussed how community members stitched into the fabric of their daily lives provided them with social support and companionship. One participant reflected on the companionship provided by a bus driver while they rode public transit:

...before that I had to ride in buses. Every single night to be safe... Well this great big huge guy named Gerald saw me and knew this wasn't something I was used to...And so he took me under his wing and I call him my guardian angel and I still see him every once in a while. (Participant \#9) 
Another participant discussed their relationship with the staff at a coffee shop they frequented. This participant elaborated on the type of support they received from the staff:

And they would always, the people there would always, "hey, here's a pot of coffee." I would pay for it of course. But there was at times, the waiter would you know, take care of it...they told me word for words, "If you don't feel safe you can come in anytime. We are open 24 hours." (Participant \#2)

Participants indicated that some community members embedded in their daily life provided them with companionship and a space to feel safe, while simultaneously looking out for their welfare. These spaces felt safe because they provided the participants with a reprieve from the outside; a space they could hang out in. Peers alleviated barriers to daily activities

Participants described how their peers experiencing houselessness broke down obstacles they encountered when conducting their daily activities. One participant reflected on how their counterparts shared detailed information about locating essential resources around Portland:

...but doing the stay at night is really where you find all your resources. I really found when you talk to other clients, other homeless people next to you left and right is telling you "man I went over here and man they gave us some sweaters...on Tuesday they got shoe day"... and you listening to other clients because if anybody know, the homeless know, you know what I'm saying? They know where the resources at, the free food." (Participant \#5)

This excerpt exemplifies the sense of community that is present between people experiencing houselessness. These individuals help each other out, and they ensure that their peers have the resources necessary for survival. Others noted that their peers helped 
them navigate the housing application process. Individuals living unhoused shared pertinent information regarding employment opportunities available to those searching for work. Participants discussed how they benefited from the social support and companionship offered by their peers. Experienced individuals offered viable information to their counterparts who were newly unhoused.

\subsection{Loss of autonomy}

\section{$\underline{\text { No control over daily schedule }}$}

Participants who lived in shelters indicated that they weren't able to control their own daily schedules, such as what time they wanted to get up and when they wanted to eat their meals. One participant elaborated on their sentiments regarding the inability to control their daily schedule:

...the shelter that I lived in...you had to be there at a certain time or you missed your meal. And you had to be up at a certain time, which was always like 6:30 or 7 o'clock...sometimes I just didn't feel like moving but I had to get up and move. Even though I was sick and I was dying then...and then, some of the mornings it was cold in the morning and I had to get up and be out. (Participant \#6)

This participant was suffering from a chronic health condition, so the inability to control their schedule not only impacted their wellbeing, but also their ability to properly manage their condition. Other participants discussed the challenges of abiding by shelters' rules and daily protocols. Participants noted that the enforcement of an early wake up time was typical, yet not preferred by the majority of them. Some participants expressed that they were not given a meal if they did not return to the shelter at the time they were being offered. Participants indicated that they wanted more control over their daily schedules while living in shelters. Modifying living environment to accommodate needs was unattainable 
Participants who reported living in shelters indicated that it was difficult to modify the physical environment to accommodate individual needs. One participant discussed the challenges of navigating their living environment with a mobility aid:

At the shelter...because I had a walker, I felt like I was in everyone's way. I really was. I wasn't the only one with a walker, there were other women in my age range and a lady with a wheelchair, so there wasn't a lot of place for that [mobility aids]. Because really you are taking up space for more than one person. (Participant \#4)

This excerpt illustrates the unique challenges an older adult may experience when they are living without housing. Other participants discussed how the living environment in shelters was not optimal for their physical or mental health, and the ability to control the environment to meet their health and safety needs was difficult. One participant reflected on their time living in a shelter with a chronic health condition:

But in this shelter, and these shelters, they're allowed to anybody and the thing about that is they don't care whether they cough in your face or sneeze your way. They don't know anything about covering their mouths. And see, that was real threatening for my condition. But as far as my dialysis, you know, that was real threatening for that. And I need not to be in that predicament. (Participant \#6)

The majority of participants indicated that shelters in the Portland metro area were not equipped to accommodate the needs of older adults experiencing houselessness. Others discussed how they encountered barriers to acquiring privacy in shelters. Participants disclosed that the staff in shelters did not abide by their requests to bathe or use the bathroom privately. Participants who lived outside indicated that it was difficult to keep their surrounding living environment clean due to external factors outside of their control. Participants who lived outside and in shelters described the safety issues they 
encountered within their immediate environment, contributing to a disruption in their nightly sleeping patterns.

\subsection{Housing optimized quality of life}

\section{$\underline{\text { Housing and ADLs/IADLs }}$}

Participants discussed how housing provided them with the ability to easily conduct their daily activities within their own space. One participant discussed how housing improved their ability to prepare and consume meals:

I cook all the time. I don't like doing dishes. And I'm eating even better than I was before...sometimes I'll sit and I'm planning meals and I'm like "oh I used to eat this all the time"...So I'll put it on my list of maybe this is something I'll make in the future...I'm happier because I have my own little space. (Participant \#7)

Other participants indicated that they can receive phone calls and talk on the phone when they need to. Others noted how making and attending appointments became easier to do with housing. Participants discussed the housing amenities that made their daily tasks easy to accomplish, such as kitchen appliances and an accessible bathroom. One participant reflected on how their apartment organically created a network of social support that provided them with reliable companionship from their neighbors.

\section{Housing restored autonomy}

Participants elaborated on how housing improved their independence and their ability to make their own decisions. One participant reflected on their sentiments when they acquired appliances for their apartment:

I was so proud of myself. I got a microwave and microwave stand all by myself. You know, I cried when I got home because it shouldn't have took me as long as it did to do it, but I try to do the best I can. (Participant \#2) 
Other participants discussed how they now have the capability to lay down or rest when they want to. Participants discussed the importance of being able to own and take care of pets and household plants in their home. Participants indicated they can choose when they want to get up and eat meals. The majority of participants noted that it was important to have their own space to accomplish their daily activities. 


\section{CHAPTER 6: DISCUSSION, POLICY IMPLICATIONS \& FUTURE RESEARCH}

The primary objective of this research was to examine how living unhoused impacted older adults' ability to conduct their daily activities. This research additionally explored how entities within the participants' communities intervened to alleviate barriers to performing their daily activities. This chapter evaluates the implications of the study's findings, policy suggestions, strengths and limitations of research, and a discussion of future research.

\subsection{Discussion}

My research found that living without housing negatively affected older adults' ability to conduct their ADLs and IADLs on a daily basis. This finding is consistent with the literature evaluating how houselessness significantly worsened the capacity for older adults to conduct their ADLs and IADLs independently (Cimino et al., 2015; Brown et al., 2012).

My research did not use the ADL and IADL indices to assess whether formerly unhoused older adults were able to accomplish those activities independently, but rather to evaluate if this index was applicable to older adults living without housing. Participants accomplished the majority of ADLs and IADLs when they experienced houselessness, but living without housing significantly impacted their ability to perform those daily activities. Two notable IADLs, specifically planning meals and maintaining the household, were not discussed by the participants within the context of their day-today activities while they lived unhoused. The participants did not discuss planning meals because they could not control their meal schedule, nor could they access a kitchen to prepare food. And managing the household was not an activity they performed because 
they did not have a house to maintain. The aforementioned IADLs were only discussed by the participants during our conversations on the impact of housing on their everyday lives. One participant described the transformation of their eating habits when they acquired housing, while other participants described how they can now take care of pets, plants, and own furniture, which are all components of household management (Edemekong et al., 2019). My data proves that the IADL scale used to assess older adults centers the experiences of older adults living in housing, and excludes the experiences of older adults living without housing.

Maintaining social support and managing transportation were critical to the survival of these older adults experiencing houselessness, who emphasized these two IADLs as pivotal activities. Forming relationships and alliances with their peers helped them locate the resources they needed to survive (i.e. food, winter clothing), and maintaining relationships with community members enabled them to access alternative spaces (i.e. coffee shops) to feel safe from the outside. Accessing public transportation was critical for getting to housing and doctor appointments, employment opportunities, and places that provided the participants with essential resources, such as the library or a community based organization. ADLs are essential to accomplish for survival, but my data found that some IADLs were just as critical to the survival of older adults experiencing houselessness.

Some activities that are vital to daily life (e.g., using the bathroom, bathing) were difficult to perform because the participants lacked access to physical space or resources to perform those activities efficiently, which was a direct result of living without housing; and a result of the perception of and treatment of people who are living unhoused. 
Participants indicated that bathroom facilities were inaccessible or lacking privacy. Others expressed that it was difficult to keep up with bathing or grooming because they did not have the resources to perform those tasks daily. The inability to conduct some ADLs was detrimental to some participants' sense of dignity. These findings highlight the physical and emotional consequences of houselessness on older adults' ability to perform their daily activities. These participants faced additional challenges (i.e. limited mobility, chronic illnesses) that shaped their experiences and made the performance of daily activities even more difficult without access to housing.

Advocates for personal hygiene recognize that the lack of access to bathroom facilities and hygiene products among people experiencing houselessness is a human rights issue. Organizations and advocacy groups in Portland responded to this urgent need by erecting bathroom stalls, and hosting events that give individuals experiencing houselessness access to personal hygiene products (Waldroupe, 2017). The Islamic Social Services of Oregon State (ISOS) hosts the "Day of Dignity" event in Portland. On this day, local vendors gather in public space and provide resources such as hygiene kits, medical care, haircuts to people in need. These events are critical because they provide essential services and resources to people in the community who do not have regular access to these necessities ("Day Of Dignity," n.d.).

This research additionally discovered that these older adults' communities served as a system of support that enabled them to perform their ADLs and IADLs while living unhoused. Entities on the community level intervened to optimize their quality of life by alleviating barriers to daily activities. This finding on community and ADL and IADL 
assistance is consistent with scholars who argue that community support is vital for the wellbeing of older adults living unhoused (Bazari et al., 2018; WaldBrook, 2013).

The participants in this study defined what the term "community" meant to them, and based on their responses, it was determined that the term community can refer to a community organization, a community spot, their peers, or community members stitched within the fabric of their daily life. All of these entities were part of a network that resided within these older adults' neighborhoods. Community-based organizations and non-profit cafes in Portland were the most common types of organizations discussed by the participants. These organizations provided non-judgmental spaces that offered them with both tangible and intangible resources, such as a place to hang out during the day. Participants discussed how those community organizations provided them with the means to access transportation, mental support and companionship, and the resources to conduct their ADLs. Others indicated that their peers helped to alleviate barriers to daily activities. The library provided a space for participants to conduct their IADLs more efficiently. Bus drivers and coffee shop workers provided some participants with social support when they were living unhoused. The findings of this study demonstrate how these older adults' communities were an integral component of their daily life that improved their wellbeing when they were living unhoused.

The findings of this research were consistent with the framework guiding this study, community gerontology (Greenfield et al., 2018). The participants described what community meant to them during the period they were living unhoused, and then discussed the strategies by which their community life intervened to make their daily activities easier to perform on a daily basis. The entities on the community level 
influenced individual outcomes by providing older adults who experienced houselessness with resources to conduct their daily activities efficiently. This, in turn, optimized their quality of life.

Based on this framework, I expected to find that various entities within the participants' communities intervened to create an optimal environment for them to perform their daily activities. But it was surprising to discover that some participants' meanings of community included unanticipated community members, such as persons performing their everyday jobs in their communities (i.e. bus drivers). These groups of individuals may not be experts on aging, yet they offered support at a time when it was imminently needed by the older participants living unhoused. The community gerontology framework urges researchers to identify how the macro-level, meso-level and micro-level are interconnected (Greenfield et al., 2018). The findings in this study indicated that the macro-level, in this case houselessness, influenced entities at the community level to intervene and make a positive impact on the individual outcomes of unhoused older adults.

The final finding of this research was that older adults experiencing houselessness were stripped of their autonomy. The lack of autonomy made it difficult for them to conduct their daily activities without housing. The majority of the participants did not have the ability to modify or control their living environment when they were living unhoused. This finding is consistent with other research conducted on autonomy and older adults experiencing houselessness (Kushel, 2011; Brown et al., 2015).

In my study, participants discussed how they could not control their own schedules while living in shelters. Others indicated that they experienced privacy issues 
when attempting to perform their daily activities. The majority of participants evaluated their autonomy within the context of aging. For example, participants discussed how shelters were not designed for older adults. Other participants discussed how living in a shelter was detrimental for their chronic health conditions. Participants juxtaposed their experiences with conducting their daily activities without housing to conducting those activities in their recently acquired apartments.

Participants overwhelmingly indicated that housing improved their quality of life because they were able to conduct their daily activities more proficiently within their own space. This finding is consistent with research on housing and the improved quality of life of older adults who experienced houselessness (Brown et al., 2015; Garibaldi et al., 2005). My research highlighted the importance of maintaining autonomy in later life, especially for older adults living unhoused. The participants benefited from housing because it improved their ability to perform their daily activities, and they obtained agency over their daily schedules.

\subsection{Policy implications}

The changing demographics of the population of people experiencing houselessness needs to be the center focus for policy makers and planners. The following recommendations must be at the forefront of service design.

\section{$\underline{\text { Universal public transportation access }}$}

Public transportation was a popular mode of transport used by many participants. Given the data acquired in this study, public transportation in the city of Portland must be free and accessible for older adults $(50+)$ who are living without housing. Public transit is a public good because it is a vital component of unhoused older adults' daily lives. Public 
transit was not only used as a way for them to get around their living environment, but as a way for them to attend housing appointments, doctors' appointments, and for safety precautions. Public transportation served as the means for these older adults to accomplish their daily tasks and to access vital community resources. Some participants rode the bus throughout the night when they were unable to stay in a shelter, viewing it as an important safety net.

The high cost of transit was a barrier for ridership among older adults who lived unhoused. The city of Portland must encourage older adults experiencing houselessness to utilize public transportation by making it free to use. Free public transportation would improve individual outcomes by providing them with a reliable method to accomplish daily activities and access vital community resources that are often clustered in the Downtown Portland area. Some participants lived on the periphery of Portland, so free transit could have provided them with a way to easily access those resources. The TriCounty Metropolitan Transportation District of Oregon currently offers discounted transit fares for low-income persons and adults over 65, with proof of eligibility ("Honored Citizen Fares," 2021). Transportation is an important IADL, and universal public transit access would eliminate the monetary barrier that prevented unhoused older adults from using this service. Based on the research in this study, it is recommended that the city of Portland make public transportation free of cost to all riders. Kansas City, MO was the first major city to propose and roll out universal transportation access in 2020 . The city implemented a no-fare transit program to bring about equal access to transportation (Bliss, 2019). Kansas City's free transportation plan can serve as a model for the city of Portland to implement in order to eliminate barriers to transportation access and use. Free 
public transit would provide older adults living unhoused with an equitable opportunity to move around their neighborhood to accomplish their daily tasks. Portland can begin its movement towards universal public transportation by providing people with no address a free transit pass.

$\underline{\text { Age-inclusive shelters }}$

Given the study's findings regarding the decreased autonomy of unhoused older adults, gerontologists must work with shelters to develop a screening tool to help identify the needs of older adults $(50+)$ staying in shelters. With this tool, staff members can identify if clients are experiencing challenges with ADLs and IADLs, limited mobility, or chronic health conditions. This tool can gather important data on the unique challenges accompanying older adults experiencing houselessness. This tool would additionally help guide the staff in providing person-centered care to older adults living unhoused. Using the person-centered care model as a guide for implementation, the staff can consider the needs of older clients that would help optimize their health and quality of life (Coulourides Kogan et al., 2016). For example, older adults can indicate the time they want to wake up, the time they want to eat meals, or the time they need to return to the shelter during the day to rest and recover. This screening tool would help restore autonomy by providing unhoused older adults with the accommodations needed to enhance their quality of life.

Improving the physical environment of shelters is also important for optimizing the wellbeing of unhoused older adults. It is recommended that shelters design their spaces to accommodate the needs of persons with all abilities. Shelters nationwide must retrofit their spaces to meet the requirements of the diverse population living unhoused. 
Common spaces and doorways should be wide enough to accommodate mobility aids (i.e. wheelchairs, scooters); single beds should be prioritized over bunk beds (Freed, 2015). One participant indicated that top bunks were challenging for them to access, so single beds may most benefit people with limited mobility. Enacting a shelter specifically for older adults $(50+)$ and persons with disabilities would be the most ideal solution, but shelters can take meaningful steps to make their spaces more accessible to persons of all ages and abilities.

\section{ADL \& IADL scales for older adults experiencing houselessness}

This study utilized the Katz activities of daily living (ADL) scale and the Lawton instrumental activities of daily living (IADL) scale as a guide to understand how living unhoused impacted older adults' ability to perform their daily activities (Wallace \& Shelkey, 2007; Graf, 2008). Given my findings that some activities featured on this commonly-used scale were critical to survival (social support, transportation), while others were not performed by participants (managing the household, planning meals), gerontologists must design ADL and IADL scales that are applicable to older adults experiencing houselessness. These scales will be different from the traditional ADL and IADL scales; they will not assess whether or not these activities can be performed independently, but rather assess if older adults have the resources to perform these activities when living unhoused. These ADL and IADL scales can be utilized by professionals working with this population (i.e. shelter staff, community-based care staff) when assessing older clients. Shelter staff, for example, must inquire about an older adults' social support system and transportation habits upon seeking shelter. Staff can then assess which resources their clients need to accomplish their daily activities, whether 
it be a free bus pass, a peer mentor, or a map of available and accessible bathroom facilities in the Portland area.

Some scholars have argued that the ADL and IADL scales are not applicable to their populations. Jitapunkul and colleagues (1994) produced a culturally specific ADL index to assess the independence of older adults living in Asia (Jitapunkul et al., 1994). The researchers highlighted an important limitation of Western ADL and IADL scales, which was the lack of usability across different cultures and experiences (Jitapunkul et al., 1994). Jitapunkul and colleagues' (1994) model can serve as a guide for gerontologists who develop ADL and IADL scales for older adults living without housing. More research is needed to develop ADL and IADL scales that are pertinent to older adults experiencing houselessness, but my data can be utilized to understand the activities that are essential to the survival of older adults living unhoused.

\section{Expand Multnomah County's Gatekeeper Program}

Community members performing their everyday jobs in Portland were a vital source of support and companionship for some participants. I chose to identify these community members as Gatekeepers, a term that refers to non-traditional outreach by community members to older adults in need of support. Gatekeepers become acquainted with these individuals through their line of work, such as a mail person. Gatekeepers are formally trained to recognize signs of distress in older adults (The Gatekeeper Program, n.d.). Multnomah County's Gatekeeper Program is an organized effort that provides community members with the resources to identify and respond to older adults or persons with disabilities in need of assistance. Trained Gatekeepers can refer individuals to social service workers (The Gatekeeper Program, n.d.). 
Based on my study, I recommend that the Gatekeeper Program widen its scope to include training on how to support older adults experiencing houselessness. The Gatekeeper Program does not specifically indicate that their tools can be applicable to older adults experiencing houselessness; the language of the Program implies that their intention is to reach older adults who have access to housing (The Gatekeeper Program, n.d.). This Program has the potential to improve the lives of older adults experiencing houselessness by creating an organized effort to look out for their welfare. The Gatekeeper Program already has the tools and resources to conduct training at workplaces around the county, so their efforts must be expanded to reach more employers around the Portland area, especially public transit employees. Gatekeeper training would provide more workers around Portland with the proper tools to intervene and connect older adults experiencing houselessness with the proper resources. The expansion of the Gatekeeper Program can start immediately because the framework exists and it has the potential to make a meaningful impact on older adults experiencing houselessness.

The city of Portland has already identified age-friendliness as a policy action plan. This policy could be leveraged to benefit older adults experiencing houselessness because the action plan includes prioritizing older adults in new planning initiatives, including housing with services (The City of Portland, OR, 2020).

6.3 Conclusion and future research

This research examined the impact that living unhoused had on older adults' ability to conduct their daily activities. This study additionally evaluated the interventions on the neighborhood level that supported unhoused older adults' ability to perform their daily activities. 
The results indicated that living without housing significantly impacted older adults' ability to conduct their ADLs and IADLs. Entities embedded in the participants' communities alleviated challenges associated with daily activities by providing them with tangible and nonmaterial resources during the period they were living unhoused. The results also indicated that unhoused older adults were stripped of their autonomy, but housing was the best solution for reinstating agency and optimizing the ability to conduct daily activities within a modifiable space.

Future research is needed to investigate the impact of houselessness on currently unhoused older adults' ability to conduct their daily activities. This research was limited to the experiences of formerly unhoused older adults, but it is important to understand the daily challenges of unhoused older adults in the present. Researchers must utilize innovative methodologies (i.e. go-along method) to provide environmental context to the participants' daily experiences and challenges. Additional research is needed on the differential experiences of unhoused older adults based on race and ethnicity.

Future research is needed to investigate how and if free transit would benefit older adults living unhoused. Scholars must conduct research with older adults experiencing houselessness to evaluate their public transportation habits and determine how free public transportation would optimize quality of life and enable public transportation usage. More research is also needed on formerly unhoused older adults to understand the housing models that are best equipped to enhance their quality of life. Researchers must investigate the importance of housing communities that foster the growth of social networks between older adults and their neighborhoods. This research indicated that 
unhoused older adults received an abundance of support from their communities, and this relationship must be maintained after acquiring housing.

This research revealed that living unhoused significantly inhibited ADL and IADL performance in later life. This research indicated that the community life of unhoused older adults played a critical role in alleviating challenges to daily activities. This research viewed the entities at the community level as powerful agents of change that optimized the quality of life of unhoused older adults. 


\section{REFERENCES}

Abramovich, I.A. (2012). No Safe Place to Go - LGBTQ Youth Homelessness in Canada:

Reviewing the Literature. Canadian Journal of Family and Youth, 4(1).

Barile, J., Thompson, W., Zach, M., Krahn, G., Horner-Johnson, W., \& Haffer, S. (2012). Activities of daily living, chronic medical conditions, and health-related quality of life in older adults. Journal of Ambulatory Care Management, 35(4), 292-303.

Bazari, A., Patanwala, M., Kaplan, L., Auerswald, C., \& Kushel, M. (2018). 'The Thing that Really Gets Me Is the Future': Symptomatology in Older Homeless Adults in the HOPE HOME Study. Journal of Pain and Symptom Management, 56(2), 195204.

Bliss, L. (2019). Why Kansas City’s Free Transit Experiment Matters. Bloomberg CityLab.https://www.bloomberg.com/news/articles/2019-12-13/is-free-transitthe-equity-fix-kansas-city-needs

Brown, R. T., Kiely, D. K., Bharel, M., \& Mitchell, S. L. (2012). Geriatric Syndromes in Older Homeless Adults. J Gen Intern Med., 27, 16-22.

Brown, R. T., Miao, Y., Mitchell, S. L., Bharel, M., Patel, M., Ard, K. L., ... Steinman, M. A. (2015). Health Outcomes of Obtaining Housing Among Older Homeless Adults. American Journal of Public Health, 105(7). Retrieved from https://muse.jhu.edu/article/389055/pdf.

Busch-Geertsema, V., Culhane, D. P., \& Fitzpatrick, S. (2016). Developing a global framework for conceptualizing and measuring homelessness. Habitat International, 55, 124-132.

Cameron, C., Smith, C. M., Tumilty, S., \& Treharne, G. (2013). The feasibility and acceptability of using mobile methods for capturing and analyzing data about dog-walking and human health. New Zealand Journal Of Physiotherapy, 42(2), $163-169$.

Canadian Observatory on Homelessness. (n.d.). Addressing Chronic Homelessness. In Homeless Hub. https://www.homelesshub.ca/solutions/prevention/addressingchronic-homelessness

Canadian Observatory on Homelessness. (n.d.). Hidden Homelessness. In Homeless Hub. 
Carrière, Y., \& Légaré, J. (2000). Unmet Needs for Assistance with ADLs and IADLs: A Measure of Healthy Life Expectancy. Social Indicators Research, 51, 107-124.

Carter (2011). From Exclusion to Destitution: Race, Affordable Housing, and Homelessness. Cityscape, 13(1), 33-70.

Cimino, T., Steinman, M. A., Mitchell, S. L., Miao, Y., Bharel, M., Barnhart, C. E., \& Brown, R. T. (2015). Disabled on the street: The course of functional impairment in older homeless adults. JAMA Intern Med., 175(7), 1237-1239.

The City of Portland, OR. (2020, May 7).

Mayor Wheeler Releases Proposed Budget For FY 2020-21. [Press release]. Retrieved from: https:/www.portland.gov/wheeler/news/2020/5/7/mayorwheeler-releases-proposed-budget-fy-2020-21

Cohen, C.I. (1999). Aging and Homelessness. The Gerontologist, 39(1), 5-14. Coulourides Kogan, A., Wilber, K., \& Mosqueda, L. (2016). Person-Centered Care for Older Adults with Chronic Conditions and Functional Impairment: A Systematic Literature Review. Journal of the American Geriatrics Society, 64, e1-e7.

Crane, M., Byrne, K., Fu, B., Mirabelli, F., Bartelink, A., Ryan, M., Shea, R., Watt, H., Warnes, A. (2004). The Causes of Homelessness in Later Life: Findings From a three-nation study. Helping Elders At Risk Through Homes. Retrieved from http://hearth-home.org.

Crouch, M., \& McKenzie, H. (2006). The logic of small samples in interview-based qualitative research. Social Science Information, 45(4), 483-499.

Culhane, D. P., Metraux, S., \& Byrne, T. (2013). The Age Structure of Contemporary Homelessness: Evidence and Implications For Public Policy. Analyses of Social Issues and Public Policy, 13(1), 228-244.

Day Of Dignity. (n.d.). In Islamic Social Services Of Oregon State (ISOS). http://www.i-sos.org/dignityday.php

Edemekong, P. F., Bomgaars, D. L., \& Levy, S. B. (2019). Activities of Daily Living (ADLs). In National Center for Biotechnology Information, U.S. National Library of Medicine. Retrieved from https://www.ncbi.nlm.nih.gov/books/NBK470404/.

Elwood, S.A. \& Martin, D.G. (2000). Placing Interviews: Locations and Scales of Power in qualitative research. Professional Geographer 52, 649-657. 
Fazel, S., Geddes, J., \& Kushel, M. (2014). The health of homeless people in high-income countries: Descriptive epidemiology, health consequences, and clinical and policy recommendations. Lancet, 384(9953), 1529-1540.

Fereday, J., \& Muir-Cochrane, E. (2006). Demonstrating Rigor Using Thematic Analysis: A Hybrid Approach of Inductive and Deductive Coding and Theme Development. International Journal of Qualitative Methods, 80-92.

Fransham, M., \& Dorling, D. (2018). Homelessness and Public Health. BMJ Clinical Research, 360(k214).

Fraser, J. C., \& Kick, E. (2014). Governing urban restructuring with city-building nonprofits. Environment and Planning A,46, 1445-1461.

Freed, S. (2015). Remodeling a Home to Be a Lifelong Home. AARP Livable Communities.https://www.aarp.org/livable-communities/housing/info2015/home-fit-dollars-and-sense.html

Fried, L. P. (2012). Epidemiology of Aging. In L. Goldman \& A. I. Schafer (Eds.), Goldman's Cecil Medicine (24th ed.).

Garcia, C., Eisenberg, M., Frerich, E., Lechner, K., \& Lust, K. (2012). Conducting Go-Along Interviews to Understand Context and Promote Health. Qualitative Health Research, 22(10), 1395-1403.

García, I., Giuliani, F., \& Wiesenfeld, E. (1999). Community and Sense of Community: The Case of an Urban Barrio in Caracas. Journal of Community Psychology, 27(6), 727-740.

Garibaldi, B., Conde-Martel, A., \& O’Toole, T. P. (2005). Self-Reported Comorbidities, Perceived Needs, and Sources for Usual Care for Older and Younger Homeless Adults. J Gen Intern Med, 20, 726-730.

The Gatekeeper Program. (n.d.). [Government]. Multnomah County. Retrieved May 11, 2020, from https://multco.us/ads/gatekeeper-program

Goldberg, J., Lang, K., \& Barrington, V. (2016). How to Prevent and End Homelessness Among Older Adults [Special Report]. Justice in Aging. https://www.justiceinaging.org/wp-content/uploads/2016/04/Homelessness-OlderAdults.pdf

Gonyea, J. G., Mills-Dick, K., \& Bachman, S. S. (2010). The Complexities of Elder 
Homelessness, a Shifting Political Landscape and Emerging Community

Responses. Journal of Gerontological Social Work, 53, 575-590.

Grant, R., Gracy, D., Goldsmith, G., Shapiro, A., Redlener, I.E. (2013). Twenty-five Years of Child and Family Homelessness: Where are they Now? American Journal of Public Health, 103(Supp1 2): e1-e10.

Graf, C. (2008). The Lawton Instrumental Activities of Daily Living Scale. American Journal of Nursing, 108(4), 52-62.

Greenfield, E., Black, K., Buffel, T., \& Yeh, J. (2018). Community Gerontology: A Framework for Research, Policy, and Practice on Communities and Aging. The Gerontologist, 59(5), 803-810.

Grenier, A., Sussman, T., Barken, R., Bourgeois-Guerin, V., \& Rothwell, D. (2016). 'Growing Old' in Shelters and 'On the Street': Experiences of Older Homeless People. J Gerontol Soc Work, 59(6), 458-477.

Groot, S., \& Hodgetts, D. (2015). The Infamy of Begging: A Case-Based Approach to Street Homelessness and Radical Commerce. Qualitative Research in Psychology, $12(4), 349-366$.

Guest, G., MacQueen, K. M., \& Namey, E. E. (2012). Applied Thematic Analysis. SAGE Publications.

Hahn, J. A., Kushel, M., Bangsberg, D. R., Riley, E., \& Moss, A. R. (2006). BRIEF REPORT: The Aging of the Homeless Population: Fourteen-Year Trends in San Francisco. J GEN INTERN MED, 21, 775-778.

Hallberg, L. (2008). Some thoughts about interviewing .... International Journal of Qualitative Studies on Health and Well-Being, 3(3).

Hill, H. (2019, November 1). Life on the Streets: Growing old. Street Roots News. Retrieved from https://news.streetroots.org/2019/11/01/life-streets-growing-old. Hoback, A., \& Anderson, S. (n.d.). Proposed Method for Estimating Local Population of Precariously Housed. National Coalition for the Homeless. Retrieved April 13, 2020, from https://nationalhomeless.org/publications/precariouslyhoused/Hobackreport.pdf Honored Citizen Fares. (2021). Trimet. https://trimet.org/fares/honoredcitizen.htm Hopper, K., Jost, J., Hay, T., Welber, S., \& Haugland, G. (1997). Homelessness, severe 
mental illness, and the institutional circuit. Psychiatric Services, 48(5), 659-665. Hwu, Y. (1995). The Impact of Chronic Illness on Patients. Rehabilitation Nursing, 20(4),

$221-225$.

Institute of Medicine (US) Committee on Health Care for Homeless People. (1988).

Dynamics of Homelessness. In Homelessness, Health, and Human Needs. National Academies Press (US).

Jitapunkul, S., Kamolratanakul, P., \& Ebrahim, S. (1994). The meaning of activities of daily living in a Thai elderly population: Development of a new index. Age and Ageing, 23(2), 1-5.

Kane, R. A., \& Cutler, L. J. (2015). Re-Imagining Long-Term Services and Supports: Towards Livable Environments, Service Capacity, and Enhanced Community Integration, Choice, and Quality of Life for Seniors. The Gerontologist, 55(2), $286-295$.

Katz, S., Ford, A. B., Moskowitz, R. W., Jackson, B. A., \& Jaffe, M. W. (1963). Studies of Illness in the Aged The Index of ADL: A Standardized Measure of Biological and Psychosocial Function. JAMA, 185(12), 914-919.

Kellogg, F. R., \& Horn, A. (2013). The Elderly Homeless: A Study Comparing Older and Younger Homeless Persons, With Three Case Histories. Care Management Journals, 13(4), 238-245.

Khouri, A. (2018, June 13). High cost of housing drives up homeless rates, UCLA study indicates. Los Angeles Times. https://www.latimes.com/business/la-fi-uclaanderson-forecast-20180613-story.html

Kim, M.-S., \& Kim, J.-I. (2015). Relationship Among the Health State, Daily Living Activities (ADL, IADL), Sleep State, and Depression Among Old People at Elderly Care Facilities. Journal of the Korea Academia-Industrial Cooperation Society, 16(4), 2609-2619.

Kushel, M. (2011). Older Homeless: Can We Do More? J Gen Intern Med, 27(1), 5-6.

Kushel, M. (2019, May). Aging Among Homeless Populations: Causes, consequences, solutions. Presented in Portland, OR. Portland, OR.

Law, J. \& Urry, J. (2004). Enacting the social. Economy and Society, 33, 390-410. 
Leung, L. (2015). Validity, reliability, and generalizability in qualitative research.

Journal

of Family Medicine and Primary Care, 4(3), 324-327.

Levine, C., Reinhard, S., Lynn Friss, F., Steven, A., \& Andrea, H. (2003). Family

Caregivers on the Job: Moving Beyond ADLs and IADLs. Generations, 4, 17-23.

Liang, X., Liu, Y., \& Qui, T. (2020). Livability Assessment of Urban

Communities considering the Preferences of Different Age Groups. Complexity, 2020, 1-15.

Martijn, C. \& Sharpe, L. (2006). Pathways to Youth Homelessness. Soc Sci Med, 62(1), $1-12$.

McDonald, S. (2020, March 13). COVID-19: What State and Local Leaders Can Do for Homeless Populations. National Alliance to End Homelessness.

https://endhomelessness.org/covid-19-what-state-and-local-leaders-can-do-forhomeless-populations/

Metraux, S., Eng, N., \& Culhane, D. P. (2011). The Impact of Shelter Use and Housing Placement on Mortality Hazard for Unaccompanied Adults and Adults in Family Households Entering New York City Shelters: 1990-2002. Journal of Urban Health, 88(6), 1091-1104.

Mikkola, T. M., Polku, H., Portegijs, E., Rantanen, T., \& Viljanen, A. (2015). Self-Reported Hearing Status Is Associated with Lower Limb Physical Performance, Perceived Mobility, and Activities of Daily Living in Older Community-Dwelling Men and Women. Journal of the American Geriatrics Society, 63(6), 1164-1169.

Mlinac, M. E., \& Feng, M. C. (2016). Assessment of Activities of Daily Living, Self-Care, and Independence. Archives of Clinical Neuropsychology, 31(6), 506-516.

National Alliance to End Homelessness (NAEH). (2018, June 20). Exploring the Crisis of Unsheltered Homelessness. Alliance. https://endhomelessness.org/exploringcrisis-unsheltered-homelessness/

National Alliance to End Homelessness (NAEH). (2020). Chronically Homeless. 
Alliance.https://endhomelessness.org/homelessness-in-america/who-experienceshomelessness/chronically-homeless/

National Coalition for the Homeless. (2009). Homelessness Among Elderly Persons. https://www.nationalhomeless.org/factsheets/Elderly.pdf

National Coalition for the Homeless. (n.d.). Homelessness in America. https://nationalhomeless.org/about-homelessness/

National Low Income Housing Coalition. (2020). Advocates' Guide 2020. National Low Income Housing Coalition. https://nlihc.org/explore-issues/publicationsresearch/advocates-guide

Nelson, J. A., Onwuegbuzie, A. J., Wines, L. A., \& Frels, R. K. (2013). The Therapeutic Interview Process in Qualitative Research Studies. The Qualitative Report, $18(40), 1-17$.

Ng, S., Rizvi, S., \& Kunik, M. E. (2013). Prevalence of Homeless Older Adults and Factors Causing Their Homelessness: A Review. The Internet Journal of Geriatrics and Gerontology, 8(1), 1-8.

Noordzij, J.M., Beenackers, M.A., Diez Roux, A.V., \& van Lenthe, F.J. (2019). Age-friendly cities: challenges for future research. Bulletin of the World Health Organization, 97(6): 436-437.

Organisation for Economic Cooperation and Development (OECD). (2010). Pensions at a Glance 2013: OECD and G20 Indicators. http://www.oecd.org/canada/OECDPensionsAtAGlance-2013-Highlights-Canada.pdf

Pelley, L. (2017, March 23). Precarious housing means thousands may live on brink of homelessness. CBC News. https://www.cbc.ca/news/canada/toronto/precarioushousing-1.4036116

Petrusak, J., Perry, T. E., \& Hassevoort, L. (2017). Somewhere to be permanent for a minute: Time and space perceptions of older adult men experiencing chronic homelessness in Detroit. J Hum Behav Soc Environ., 27(6), 515-529.

POINT-IN-TIME Count of Homelessness in Portland/Gresham/Multnomah County, Oregon (pp. 1-61). (2019). Retrieved from http://ahomeforeveryone.net/point-intime-counts.

Rossetto, K. R. (2014). Qualitative research interviews: Assessing the therapeutic value 
and challenges. Journal of Social and Personal Relationships, 31(4), 482-489.

Shelby, H. (2016). Why Place Really Matters: A Qualitative Approach to Housing Preferences and Neighborhood Effects. Housing Policy Debate, 27(4), 547-569.

Sheller, M., \& Urry, J. (2006). The New Mobilities Paradigm. Environment and Planning A: Economy and Space, 38(2).

Smith, R.J, Lehning, A.J., \& Kim, K. (2018). Aging in Place in Gentrifying Neighborhoods: Implications for Physical and Mental Health. Gerontologist, 58(1), 26-35.

Souza, A. M., Tsai, J. H.-C., Pike, K. C., Martin, F., \& McCurry, S. M. (2020).

Cognition,

Health, and Social Support of Formerly Homeless Older Adults in Permanent Supportive Housing. Innovation in Aging, 4(1).

Szanton, S. L., Thorpe, R. J., Boyd, C., Tanner, E. K., Leff, B., Agree, E., Xue, Q.-L., Allen, J. K., Seplaki, C. L., Weiss, C. O., Guralnik, J. M., \& Gitlin, L. N. (2011). Community Aging in Place, Advancing Better Living for Elders: A BioBehavioral-Environmental Intervention to Improve Function and Health-Related Quality of Life in Disabled Older Adults. The American Geriatrics Society, 59(12), 2314-2320.

Tan, H. (2018). Whose 'fault' is it? Becoming homeless in Singapore. Urban Studies, 55(16), 3579-3595.

The U.S. Department of Housing and Urban Development (HUD). (2018). The 2018 Annual Homeless Assessment Report (AHAR)(p. 96).

WaldBrook, N. (2013). Formerly Homeless, Older Women's Experiences with Health, Housing, and Aging. Journal of Women \& Aging, 25, 337-357.

Waldroupe, A. (2017). Portland-area communities address hygiene needs on the streets. Street Roots. https://www.streetroots.org/news/2017/10/06/portland-areacommunities-address-hygiene-needs-streets

Wallace, M., \& Shelkey, M. (2007). Katz Index of Independence in Activities of Daily Living (ADL). The Hartford Institute for Geriatric Nursing.

Weiss, R. S. (1994). Learning from strangers: The art and method of qualitative interview studies. New York, NY: Free Press. 
Woolley, E. (2015, July 24). What are the pathways to homelessness in old age?

Canadian Observatory on Homelessness. https:/www.homelesshub.ca/blog/whatare-pathways-homelessness-old-age

The World Health Organization (WHO). (n.d.). Proposed working definition of an older person in Africa for the MDS Project. Retrieved from

https://www.who.int/healthinfo/survey/ageingdefnolder/en/. 